\title{
Whole genome based insights into the phylogeny and evolution of the Juglandaceae
}

\author{
Huijuan Zhou ${ }^{1,2+}$, Yiheng $\mathrm{Hu}^{2+}$, Aziz Ebrahimi ${ }^{3}$, Peiliang Liư ${ }^{2}$, Keith Woeste ${ }^{3}$, Peng Zhao ${ }^{2 *}$ (I) and \\ Shuoxin Zhang ${ }^{1 *}$
}

\begin{abstract}
Background: The walnut family (Juglandaceae) contains commercially important woody trees commonly called walnut, wingnut, pecan and hickory. Phylogenetic relationships and diversification within the Juglandaceae are classic and hot scientific topics that have been elucidated by recent fossil, morphological, molecular, and (paleo) environmental data. Further resolution of relationships among and within genera is still needed and can be achieved by analysis of the variation of chloroplast, mtDNA, and nuclear genomes.

Results: We reconstructed the backbone phylogenetic relationships of Juglandaceae using organelle and nuclear genome data from 27 species. The divergence time of Juglandaceae was estimated to be $78.7 \mathrm{Mya}$. The major lineages diversified in warm and dry habitats during the mid-Paleocene and early Eocene. The plastid, mitochondrial, and nuclear phylogenetic analyses all revealed three subfamilies, i.e., Juglandoideae, Engelhardioideae, Rhoipteleoideae. Five genera of Juglandoideae were strongly supported. Juglandaceae were estimated to have originated during the late Cretaceous, while Juglandoideae were estimated to have originated during the Paleocene, with evidence for rapid diversification events during several glacial and geological periods. The phylogenetic analyses of organelle sequences and nuclear genome yielded highly supported incongruence positions for J. cinerea, J. hopeiensis, and Platycarya strobilacea. Winged fruit were the ancestral condition in the Juglandoideae, but adaptation to novel dispersal and regeneration regimes after the Cretaceous-Paleogene boundary led to the independent evolution of zoochory among several genera of the Juglandaceae.
\end{abstract}

Conclusions: A fully resolved, strongly supported, time-calibrated phylogenetic tree of Juglandaceae can provide an important framework for studying classification, diversification, biogeography, and comparative genomics of plant lineages. Our addition of new, annotated whole chloroplast genomic sequences and identification of their variability informs the study of their evolution in walnuts (Juglandaceae).

Keywords: Diversification, Divergence time, Genome, Juglandaceae, Phylogenomics, Plastome

*Correspondence: pengzhao@nwu.edu.cn; sxzhang@nwsuaf.edu.cn

${ }^{\dagger}$ Huijuan Zhou and Yiheng Hu contributed equally to this work

${ }^{1}$ College of Forestry, Northwest A\&F University, Yangling 712100, Shaanxi,

China

${ }^{2}$ Key Laboratory of Resource Biology and Biotechnology in Western

China, Ministry of Education, College of Life Sciences, Northwest

University, Xi'an 710069, Shaanxi, China

Full list of author information is available at the end of the article

\section{Background}

Phylogenomics applies genomic data to reconstruct the evolutionary biology of organisms [1-3], including the resolution of evolutionary relationships among and within family clades [4-7], genera, and closely related species [8-10]. Next generation sequencing (NGS) has made the generation of large-scale genomic data easier, cheaper, and greatly increased the availability 
complete chloroplast genomes [6,9] and whole genome resequencing data [11]. The plastid genome has provided insight into molecular phylogeny and evolutionary relationships at many taxonomic levels $[4,9,12$, 13]. Foundational genetic studies of the Juglandaceae were based on analysis of selected loci [14-16]. Whole genome scale studies can be useful-and in some cases necessary-supplements to previous research. Whole genomes are particularly suited to resolution of evolutionary relationships where sequence variation is limited by taxonomic level, early divergence, large difference in morphology, rapid speciation or slow genome evolution $[7,17-20]$.

The walnut family (Juglandaceae) is distributed in both the Old and New World, from North and South America to southeastern Europe, eastern Asia, and southeastern Asia, from $\mathrm{S} 10^{\circ}$ to $\mathrm{N} 49^{\circ}$ [21-27] (Fig. 1). All species of Juglandaceae are perennial woody plants [28-32]. The accepted phylogeny for the Fagales shows the Juglandaceae is monophyletic and most closely related to the Myricaceae [28-30]. The Juglandaceae are lumped with five other families (Betulacea, Casuarinaceae, Fagaceae, Nothofagaceae, and Ticodendraceae) to constitute the order Fagales [28, 31, 33-38].
The Juglandaceae contains around ten extant genera (Juglans, Pterocarya, Cyclocarya, Platycarya, Carya, Engelhardia, Alfaroa, Alfaropsis, Oreomunnea, and Rhoiptelea) comprised of ca. 60 total species [35-41]. Members of the family are considered some of the most important nut, medicinal, and timber trees. The phylogenetic relationships among and within genera of Juglandaceae are a complex puzzle that has been the subject of numerous studies [16, 24, 30, 31, 35-41]. Comparative morphology, i.e., primarily interpretation of the floral parts, was used to develop the classically accepted taxonomy and phylogeny of the family [21, 22, 39-45].

Although studies based on a limited number of loci (chloroplast DNA fragments) and fossil evidence have greatly advanced our understanding of Juglandaceae [16, 17, 23-27, 30, 31], some relationships within Juglans, Carya, and Pterocarya are weakly supported or conflicting; especially the relationship of Platycarya to Carya, and the position of Cyclocarya and Pterocarya in relation to Juglans [16, 36]. Other issues include the placement of the Rhoipteleaceae, a monotypic family containing only the species Rhoiptelea chiliantha [36, 43]. It was placed in the Juglandaceae by APG III (2009) system (Fig. 1) [44]. Similarly, the genus Annamocarya contains only one

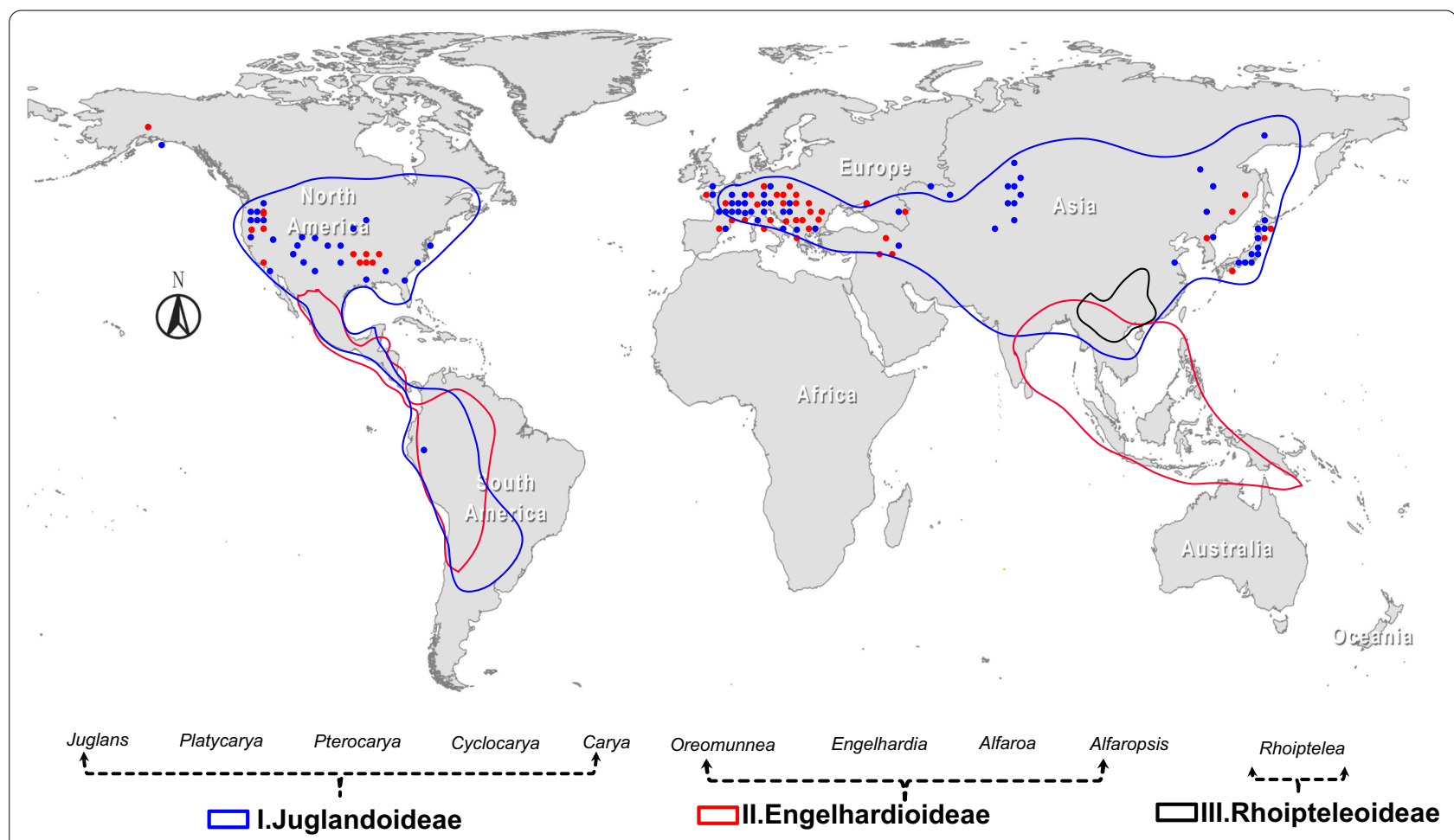

Fig. 1 Geographic distribution of modern and fossil members of the Juglandaceae. Lined regions indicate the modern distribution of ten genera belong to the three subfamilies (Juglandoideae, blue line; Engelhardioideae-red line; and Rhoipteleoideae, black line). The map used ArcGIS (version 10.0). The source locations of Juglandaceae fossils used in our analyses are colored dots. blue-Juglandoideae (Juglans, Platycarya, Pterocarya, Cyclocarya, and Carya), red-Engelhardioideae (Oreomunnea, Engelhardia, Alfaroa, and Alfaropsis), and Black- Rhoipteleoideae (Rhoiptelea) 
species, A. sinensis. Placement of Annamocarya within Carya is well-accepted [27, 35], although it shares a number of characteristics with walnuts (genus Juglans).

The evolution of the Juglandaceae remains a difficult problem too; hypothesized to have both ancient and recent extinctions and radiations [21, 27, 45], the family is considered species poor. The species that remain, however, are divergent in their ecology (wind versus animaldispersed fruit) [31], and flower development [23].

The primary goal of this study was to increase the resolution of the molecular phylogeny of the Juglandaceae by maximizing the number of taxa sampled and the number of genetic markers used [23, 28, 31]. We selected 27 Juglandaceae taxa, slightly more than half of the $\sim 60$ recognized species from three subfamilies (Engelhardioideae, Juglandoideae, and Rhoipteleoideae), and from seven of the ten worldwide genera, making this the most comprehensive study to date. We used sequence data from matrilineally (chloroplast genomes and mitochondrial protein-coding genes) and biparentally (whole genome re-sequencing of nuclear genome SNPs) inherited DNA to illuminate the evolutionary history of the Juglandaceae. We also reanalyzed phylogenetic relationships of 55 species using ITS (Internal transcribed spacers) sequences. Our goal was to (1) reconstruct the phylogenetic relationships of the family Juglandaceae based on whole chloroplast genomes, whole genome re-sequencing of nuclear genome SNPs (nrSNPs), ITS, and sixteen mitochondrial protein-coding genes (mtCDS), with an eye toward the major unresolved systematic questions in this family, (2) compare the plastid genomes of Juglandaceae, and identify the location and extent of genetic variations in these genomes across within the Juglandaceae, (3) reconstruct a time-calibrated phylogeny of the Juglandaceae based on whole chloroplast genomes, (4) reveal the timing of diversification for important nodes within the family.

\section{Results}

Sequencing, assembly, and characteristics of Juglandaceae plastome

All Juglandaceae plastomes were entirely syntenic, nonrecombining circular genomes with conserved gene content and gene order (Table 1; Fig. 2a). The raw reads and sequence depth of Juglandaceae plastomes ranged from 29,975 to $13,878,699$ bp and 0.19 to $86.54 \times$, respectively (Additional file 1: Table S1). The Juglandaceae plastome has a mean length of $160,150 \mathrm{bp}$, and ranged from 158,281 bp (Platycarya strobilacea) to 160,585 (Carya illinoinensis) with four main parts; a large singlecopy region (LSC; 87,900-90,477 bp), a small single-copy region (SSC; 18,296-18,533 bp), and two inverted repeat regions (IRs; 25,946-26,242 bp) (Table 1; Fig. 2a; Additional file 1: Table S1). The GC content of the Juglandaceae plastomes ranged from 36.1 to $36.3 \%$ (Additional file 1: Table S1). The total number of annotated genes varied from 117 to 137 , including 79-86 protein-coding genes (CDS), 30-40 tRNA genes (seven duplicated in the IRs) and 8 rRNA genes (four duplicated in the IRs) (Fig. 2a; Additional file 1: Table S1). Overall, a majority of the Juglandaceae plastomes encoded 134 genes (86 protein-coding genes, 40 tRNA genes and 8 rRNA genes) (Fig. 2a; Additional file 1: Table S1). There were four introns ( $r p l 2, r p l 16, r p s 16$, and rpoC1) located in the IRs region and 13 introns in the LSC region in each of the plastomes (Fig. 2b, c). Seven tRNA genes, trnI-CAU, trnL$C A A, \operatorname{trn} V-G A C$, trnI-GAU, trnA-UGC, trnR-ACG, and trnN-GUU were duplicated and scattered in the inverted repeat (Fig. 2a). We aligned each of the protein-coding genes (CDS) of all species. Three potential pseudogenes (infA, rpl22, and $y c f 15$ ) were identified, and their sequence verified using Sanger sequencing (Shagon Biotech, Shanghai, China) (Additional file 2: Fig. S1; Additional file 1: Table S2).

\section{Variation among walnut family based on chloroplast genome and nuclear sequencing data analysis}

Comparison of the whole chloroplast genome sequences revealed a total of 18,050 SNPs and 2496 Indels (insertions and deletions), for a total of 6594 high-quality nonredundant variant positions, or approximately 5.66 SNPs/ $\mathrm{kb}$ (Table 2; Fig. 2). A total of 4228 variant positions (64\%) were found in intergenic regions. The remaining variants affected 88 genes, leaving 41 genes unaffected (Table 2). Several regions were remarkably variable, including mat $K$ (68.0 SNPs per kb), $n d h D$ (56.5), $n d h F$ (53.5), rpoC2 (39.1), rpoB (26.5), $a c c D$ (46.8), and $y c f 1$ (101.5). A total of 1,161,468 SNPs were identified from whole genome sequencing data (Additional file 1: Table S3) based on comparison with a J. regia reference genome [46]. The SNPs number, mapping ratio, heterozygosity, and heterozygosity ratio ranged from 202,314 to $1,143,008,17.81 \%$ to $98.45 \%, 166$ to 540,829 , and $3.54 \%$ to $54.61 \%$, respectively (Additional file 1: Table S3; Additional file 3: Fig. S2). 
Table 1 Taxa and voucher information for plant material that provided Juglandaceae plastomes

\begin{tabular}{|c|c|c|c|c|c|c|c|c|c|}
\hline Species & Total length & GC $\%$ & LSC & SSC & IR & Raw reads & Mapped reads & Sequencing Platform & GenBank No. \\
\hline Alfaropsis roxburghiana & 161,164 & 36 & 90,477 & 18,531 & 26,087 & $10,435,597$ & 261,440 & Illumina Hiseq2500 & MH188300 \\
\hline Carya cathayensis & 160,300 & 36.2 & 89,715 & 18,553 & 26,016 & $7,391,021$ & 92,365 & Illumina Hiseq2500 & MH189594 \\
\hline Caryahunanensis & 160,397 & 36.2 & 89,807 & 18,532 & 26,029 & $9,303,790$ & 94,317 & Illumina Hiseq2500 & MH188303 \\
\hline Carya illinoensis & 160,585 & 36.2 & 90,030 & 18,435 & 26,060 & $9,652,336$ & 70,573 & Illumina Hiseq2500 & MH188302 \\
\hline Carya kweichwensis & 159,780 & 36.3 & 89,264 & 18,430 & 26,043 & $9,087,431$ & 236,036 & Illumina Hiseq2500 & MH188301 \\
\hline Carya sinensis & 160,195 & 36.3 & 89,541 & 18,538 & 26,085 & $13,878,699$ & 420,540 & Illumina Hiseq2500 & KX703001 \\
\hline Cyclocarya paliurus & 160,562 & 36.1 & 90,007 & 18,477 & 26,039 & $9,073,816$ & 277,193 & Illumina Hiseq2500 & KY246947 \\
\hline Juglans ailantifolia & 160,353 & 36.1 & 89,931 & 18,376 & 26,023 & $12,918,979$ & 145,907 & Illumina Hiseq2500 & MH188299 \\
\hline Juglans cathayensis & 159,730 & 36.1 & 89,333 & 18,351 & 26,023 & $13,178,238$ & 344,843 & Illumina Hiseq2000 & KX671976 \\
\hline Juglans cinerea & 160,193 & 36.2 & 89,719 & 18,406 & 26,034 & $13,018,105$ & 720,145 & Illumina Hiseq2500 & MH188298 \\
\hline Juglans hindsii & 159,929 & 36.2 & 89,597 & 18,296 & 26,018 & 29,975 & 6,646 & Roche 454 & MH188297 \\
\hline Juglans hopeiensis & 159,714 & 36.1 & 89,872 & 18,406 & 26,036 & $12,382,845$ & 517,928 & Illumina Hiseq2000 & KX671977 \\
\hline Juglans major & 160,221 & 36.1 & 89,766 & 18,372 & 26,034 & $9,407,594$ & 513,705 & Illumina Hiseq2500 & MH188296 \\
\hline Juglans mandshurica & 159,729 & 36.1 & 89,331 & 18,346 & 26,023 & $11,805,821$ & 527,970 & Illumina Hiseq2000 & KX671975 \\
\hline Juglans microcarpa & 160,065 & 36.2 & 89,637 & 18,383 & 26,022 & 85,030 & 22,781 & Roche 454 & MH188295 \\
\hline Juglans nigra & 160,301 & 36.1 & 89,840 & 18,393 & 26,034 & $13,178,283$ & 434,844 & Illumina Hiseq2500 & MH188294 \\
\hline Juglans regia & 160,367 & 36.1 & 89,872 & 18,425 & 26,035 & $3,511,124$ & $1,713,581$ & Illumina Miseq & KT963008 \\
\hline Juglans sigillata & 160,350 & 36.1 & 89,872 & 18,406 & 26,036 & $12,225,897$ & 402,317 & Illumina Hiseq2000 & KX424843 \\
\hline Platycarya strobilacea & 158,281 & 36.1 & 87,990 & 18,399 & 25,946 & $12,345,252$ & 79,584 & Illumina Hiseq2500 & MH189595 \\
\hline Pterocarya delavayi & 160,174 & 36.2 & 89,640 & 18,510 & 26,012 & $9,295,098$ & 179,137 & Illumina Hiseq2500 & MH188304 \\
\hline Pterocarya fraxinifolia & 160,246 & 36.2 & 89,783 & 18,437 & 26,013 & $9,731,800$ & 187,013 & Illumina Hiseq2500 & MH188291 \\
\hline Pterocarya hupehensis & 159,770 & 36.2 & 89,229 & 18,505 & 26,018 & $9,605,591$ & 273,616 & Illumina Hiseq2500 & MH188293 \\
\hline Pterocarya insignis & 160,207 & 36.2 & 89,728 & 18,476 & 26,006 & $9,805,922$ & 156,606 & Illumina Hiseq2500 & MH188292 \\
\hline Pterocarya macroptera & 159,941 & 36.2 & 89,517 & 18,410 & 26,007 & $9,164,994$ & 113,662 & Illumina Hiseq2500 & MH188290 \\
\hline Pterocarya stenoptera & 160,202 & 36.2 & 89,727 & 18,433 & 26,021 & $11,542,884$ & 186,936 & Illumina Hiseq2500 & MH188289 \\
\hline Pterocarya tonkinensis & 160,096 & 36.2 & 89,600 & 18,482 & 26,007 & $7,449,017$ & 160,611 & Illumina Hiseq2500 & MH188288 \\
\hline
\end{tabular}

LSClarge single copy, SSC small single copy, IR inverted repeat. Length of regions is given in number of base pairs (bp)

\section{Phylogenetic relationships of the Juglandaceae}

Based on best-fit partitioning schemes and models, the phylogenies returned from the RAxML and MrBayes analyses using 61 chloroplast protein-coding genes showed all branches highly supported (Fig. 3a). Within the Fagales, members of the Juglandaceae were closest to the Myricaceae and Betulaceae (Fig. 3b). Species within the Juglandaceae divided into three groups corresponding to the three previously described sub-families (Juglandoideae, Engelhardioideae, and Rhoipteleoideae) with
$100 \%$ bootstrap (BS) support based on mtCDS and chloroplast genomes using maximum likelihood (ML) analysis (Fig. 3a, b).

Within the Juglandoideae subfamily, the species divided into five groups, corresponding to the five genera Carya, Platycarya, Cyclocarya, Pterocarya, and Juglans that were strongly supported as monophyletic (Fig. 3a). The genus Pterocarya was most closely related to Juglans (Fig. 3). The wheel wingnut (Cyclocarya paliurus) is the sole member of its genus in Juglandaceae. It was monophyletic

(See figure on next page.)

Fig. 2 Variability of the family Juglandaceae represented over the circular map of Juglans regia, and comparison of percentage of variable characters in Juglandaceae plastomes. a Circular map comparing the chloroplast genomes of the genera of the walnut family (the reference chloroplast genome sequence NCBI accession number: KT963008; Hu et al. 2016a). The two inverted repeat regions (IRa and IRb) separate the large (LSC) and small (SSC) single copy regions, respectively. Genes represented by outside rectangles are on the positive strand, genes represented by inside rectangles are on the negative strand. Density of chloroplast SNPs is represented by a heatmap that varies from low (white) to high (dark blue). The circle depicts average SNP density estimated in 350 bp moving windows. Carya = Carya cathayensis, Rhoiptelea = Rhoiptelea chiliantha, Alfaropsis = Alfaropsis roxburghiana, Platycarya $=$ Platycarya strobilacea, Pterocarya $=$ Pterocarya fraxinifolia, Juglans $=$ Juglans ailantifolia. Comparison of percentage of variable characters in Juglandaceae plastomes. b Protein-coding genes (CDS), c Intergenic spacer (IGS) regions. The peaks labeled in blue were highly variable genes or regions 

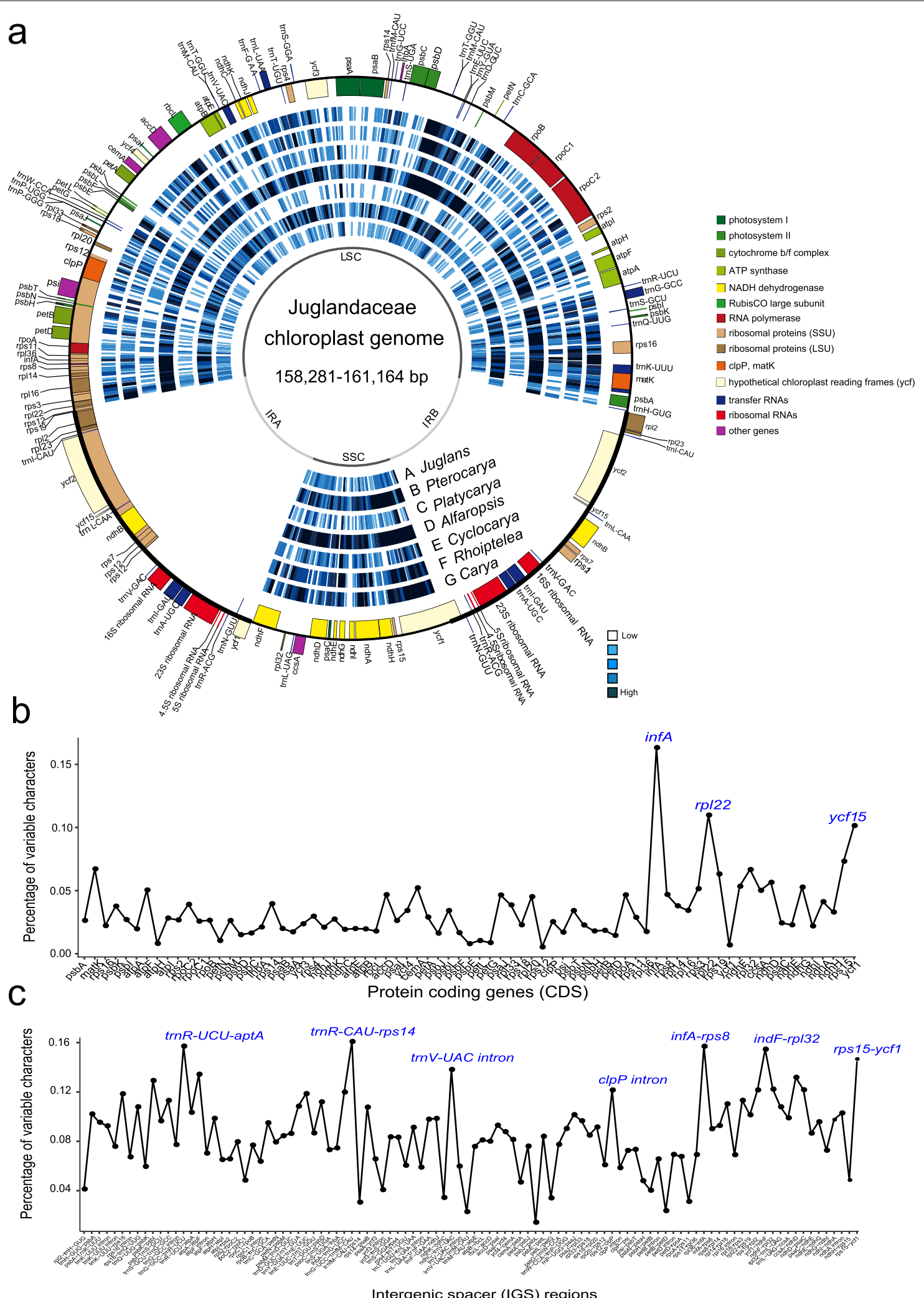

Fig. 2 (See legend on previous page.) 
Table 2 Summary of variants from all Juglandaceae genomes based on comparison with Juglans regia whole genome sequences

\begin{tabular}{|c|c|c|c|c|c|c|c|c|}
\hline Species & cp-SNPs & nr-SNPs & cp-Indels & Ts/Tv ratio & Mapped \% & Heterozygosity & Homozygosity & Het-ratio $\%$ \\
\hline Alfaropsis roxburghiana & 1959 & 215,357 & 166 & $1.17 / 1.66$ & 55.74 & 10,655 & 204,702 & 4.94 \\
\hline Carya cathayensis & 1131 & 253,730 & 288 & $1.04 / 1.43$ & 53.16 & 9,006 & 244,724 & 3.54 \\
\hline Carya hunanensis & 1066 & 275,372 & 241 & $1.14 / 1.45$ & 84.00 & 21,179 & 254,193 & 7.69 \\
\hline Carya illinoensis & 1100 & 761,308 & 268 & $1.05 / 2.28$ & 44.90 & 263,845 & 497,463 & 34.65 \\
\hline Carya kweichwensis & 1102 & 326,824 & 24 & $1.09 / 1.43$ & 66.91 & 23,680 & 303,144 & 7.24 \\
\hline Carya sinensis & 1041 & 344,322 & 5 & $1.01 / 1.56$ & 69.18 & 26,548 & 325,860 & 6.88 \\
\hline Cyclocarya paliurus & 676 & 483,874 & 9 & $0.77 / 1.43$ & 56.99 & 40,571 & 443,303 & 8.38 \\
\hline Juglans ailantifolia & 433 & 443,059 & 134 & $1.02 / 1.61$ & 37.64 & 21,704 & 421,355 & 4.89 \\
\hline Juglans cathayensis & 458 & $1,143,008$ & 23 & $1.05 / 1.61$ & 45.01 & 120,312 & $1,022,696$ & 10.52 \\
\hline Juglans cinerea & 482 & $1,014,615$ & 109 & $0.99 / 1.64$ & 71.72 & 80,304 & 934,311 & 7.91 \\
\hline Juglans hindsii & 376 & 361,913 & 46 & $1.12 / 1.43$ & 68.84 & 17,962 & 343,951 & 4.96 \\
\hline Juglans hopeiensis & 368 & 990,423 & 26 & $0.83 / 1.82$ & 61.78 & 540,892 & 449,531 & 54.61 \\
\hline Juglans major & 472 & 943,553 & 15 & $0.93 / 1.65$ & 84.57 & 73,817 & 869,736 & 7.82 \\
\hline Juglans mandshurica & 455 & $1,059,545$ & 32 & $0.97 / 1.63$ & 92.58 & 110,349 & $9,49,196$ & 10.41 \\
\hline Juglans microcarpa & 374 & 949,180 & 106 & $1.23 / 1.66$ & 98.11 & 111,259 & 837,921 & 11.72 \\
\hline Juglans regia & 0 & 742,382 & 0 & $0.00 / 2.29$ & 96.69 & 225,592 & 516,790 & 30.38 \\
\hline Juglans sigillata & 6 & $1,051,470$ & 2 & $0.20 / 2.29$ & 46.02 & 421,420 & 630,050 & 40.07 \\
\hline Juglans nigra & 478 & 682,382 & 3 & $0.94 / 1.66$ & 69.12 & 166 & 1871 & 8.14 \\
\hline Platycarya strobilacea & 1465 & 319,852 & 22 & $1.33 / 1.49$ & 97.71 & 39,263 & 280,589 & 12.27 \\
\hline Pterocarya delavayi & 495 & 686,705 & 123 & $1.09 / 1.43$ & 64.74 & 45,839 & 640,866 & 6.67 \\
\hline Pterocarya fraxinifolia & 506 & 621,411 & 103 & $1.11 / 1.42$ & 23.93 & 37,402 & 584,009 & 6.01 \\
\hline Pterocarya hupehensis & 505 & 515,964 & 75 & $1.17 / 1.45$ & 36.97 & 35,974 & 479,990 & 6.97 \\
\hline Pterocarya insignis & 506 & 589,290 & 116 & $1.00 / 1.43$ & 98.45 & 41,877 & 547,413 & 7.10 \\
\hline Pterocarya macroptera & 513 & 430,744 & 153 & $1.11 / 1.42$ & 72.96 & 23,897 & 406,847 & 5.54 \\
\hline Pterocarya stenoptera & 483 & 653,976 & 28 & $1.12 / 1.39$ & 86.64 & 53,662 & 600,314 & 8.20 \\
\hline Pterocarya tonkinensis & 487 & 547,524 & 133 & $1.05 / 1.44$ & 68.29 & 33,764 & 513,760 & 6.16 \\
\hline Rhoiptelea chiliantha & 2126 & 202,314 & 179 & $1.21 / 1.71$ & 58.22 & 11,023 & 196,822 & 4.78 \\
\hline
\end{tabular}

$c p$-SNPs the number of SNPs of chloroplast genomes, $n r$-SNPs the number of SNPs of whole genome resequencing, $c p$-Indels the number of Indels of chloroplast genomes, Ts/Tv ratio the transition/transversion ratio based on chloroplast genomes and whole genome resequencing data respectively, Mapped the mapped ratio of whole genome resequencing data used common walnut genome sequence data, Het-ratio the Heterozygosity ratio of each samples based on the whole genome resequencing data

and most closely related to Pterocarya based on chloroplast genomes (Fig. 3a). In Carya, Pecan (C. illinoinensis a North American species) was joined with the other four species of Carya (Asian hickories) with $100 \%$ BS. The cladograms supported the current division of Carya into two sections (Sect. Sinocarya, Asian hickories, i.e., $C$. cathayensis, C. hunanensis, C. kweichowensis, and C. sinensis; and Sect. Apocarya, which includes C. illinoinensis). We also confirmed that the genus Annamocarya (A. sinensis) is properly within Carya and closest to Carya Fig. 3) [27, 36-38]. The three sections within Juglans were well resolved with high bootstrap support (J. regia and J. sigillata into Sect. Juglans/Dioscaryon; J. mandshurica, J. ailantifolia, and J. cathayensis into Sect. Cardiocaryon; J. cinerea, J. nigra, J. hindsii, J. microcarpa, and J. major into Sect. Trachycaryon and Sect. Rhysocaryon) based on data from both chloroplasts and mitochondria (Fig. 3a, b). Branch lengths for J. hopeiensis/J. mandshurica and J.
regia/J. sigillata were extremely short, further supporting their recent divergence.

Based on 1,161,468 nuclear SNPs, the phylogenetic analysis showed a generally well-supported clustering topology with high bootstrap values when rooted against Populus trichocarpa as the outgroup (Fig. 3c). The resulting phylogeny identified and provided $100 \%$ support for the three sub-families that we observed in the genome-based phylogeny of the Juglandaceae (Fig. 3): Clade I (Rhoipteleoideae), clade II (Engelhardioideae), and clade III (Juglandoideae). Clade III (Juglandoideae) contained five genera Platycarya, Carya, Cyclocarya, Pterocarya, and Juglans, however, the relative placement of the three genera, Carya, Platycarya, and Cyclocarya was not consistent in the phylogenies based on the combined $\mathrm{Cp}$ and mitochondrial genomes versus the nuclear data. Although we only used one species in Platycarya, our results strongly supported the model that Cyclocarya 


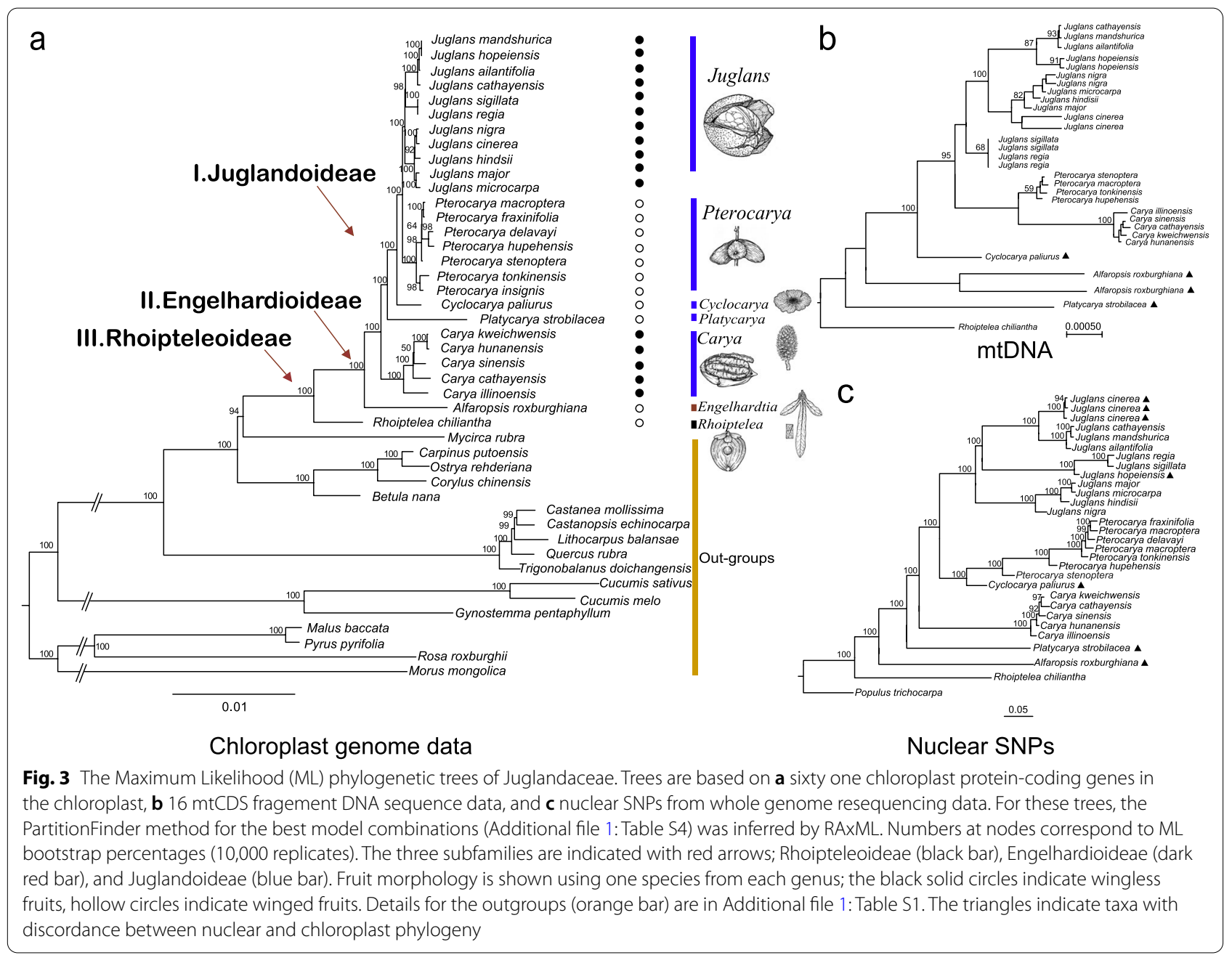

and Platycarya are monophyletic with long branches and taxa-specific SNPs (Fig. 3c; Additional file 1: Table S3). Based on nuclear SNPs, we found a strong sister relationship of Cyclocarya to Pterocarya and, secondarily, to Juglans (Fig. 3c), as suggested by Manos et al. (2007) [17] and Larson-Johnson (2016) [35].

We reconstructed the Bayesian and ML trees based on ITS sequences of 55 Juglandaceae species (Fig. S3). The resulting phylogenetic tree showed that the three subfamilies, Juglandoideae, Engelhardioideae, and Rhoiptelioideae, cluster as monophyletic branches, however, support for the genera within the Juglandoideae was weak $(<50 \%)$ (Additional file 4: Fig. S3). ITS alone produced cladograms markedly different than accepted topologies.

\section{The divergence time and historical diversification of Juglandaceae}

The stem age of Juglandaceae was estimated at 78.69 Mya (95\% highest posterior density (HPD): $76.58-80.50$ Mya). The walnut family diverged from the Myricaceae during the late Cretaceous (Fig. 4). During the

(See figure on next page.)

Fig. 4 Time-calibrated phylogenetic tree of Juglandaceae based on 61 protein-coding genes (CDS) of chloroplast genomes. Mean divergence times estimated using a relaxed molecular clock model with 6 fossil priors (red stars). Blue bars across nodes indicate 95\% HPD intervals around the mean divergence time estimates. Nodes are numbered as ages. The genera and subfamilies of Juglandaceae are shown in the figure and the geological time scale is shown below the tree. A stacked deep-sea benthic foraminiferal oxygen-isotope curve shows the evolution of global climate over the last 65 Mya, as modified from Zachos et al. (2001, 2008) [47, 48]. PETM Palaeocene-Eocene thermal maximum, ETM Eocene thermalmaximum, P/ pliocene. Reprinted by permission from Macmillan Publishers Ltd: Nature (451, 279-283), copyright (2008). 


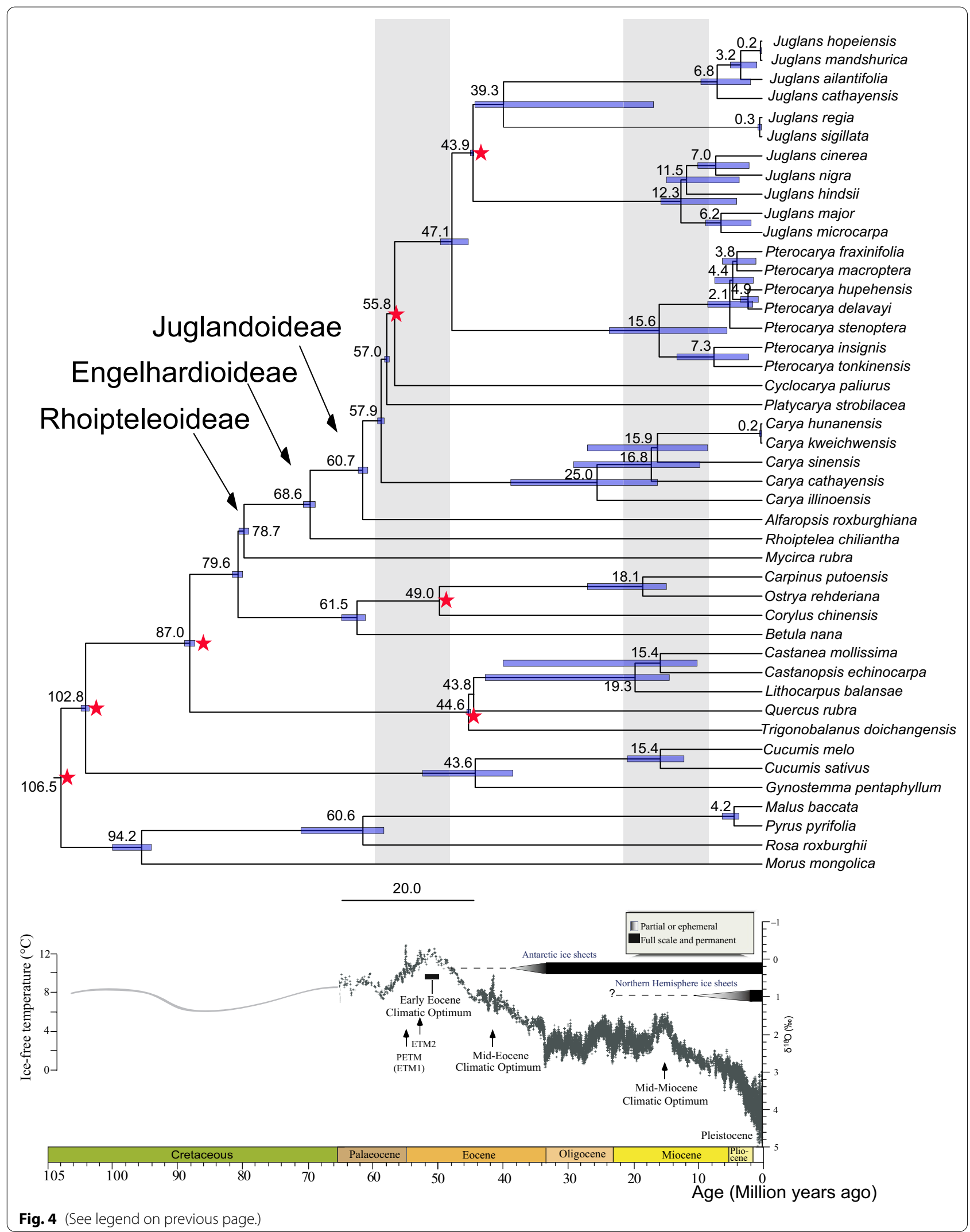


Middle Cretaceous to Late Cretaceous, the three subfamilies Rhoiptelioideae, Engelhardoideae and Juglandoideae diverged at 68.64 Mya and 60.65 Mya (95\% HPD: 58.98-70.98 Mya), respectively. The crown age of the genus Carya was estimated at 57.88 Mya (95\% HPD: 56. 67-60.32 Mya) during the Late Paleocene, Platycarya at 56.99 Mya (95\% HPD: 56.80-58.80 Mya), and Cyclocarya paliurus at 55.80 Mya (95\% HPD: $54.30-57.30 \mathrm{Ma}$ ). The divergence of Pterocarya and Juglans was estimated at 47.10 Mya (95\% HPD: 43.93-50.93 Mya) during the Early Eocene. Most genera of Juglandaceae diverged from 50.93 to 61.98 Mya in the relatively warm and dry climate of the Middle Paleocene to the Early Eocene (Fig. 4).

\section{Discussion}

\section{Comparison of the genomes of the Juglandaceae}

Both genome size and GC content among Juglandaceae plastomes were consistently more than the median genome size and GC content for land plant plastomes (Table 1). The nucleotide variability (Pi) across all 27 plastomes of Juglandaceae included in this study was 0.00791 (Fig. 2). Coding regions with the highest variation included matK, atpI, rpoC2, rps14, aacD, psaI, ycf4, cemA, rpl33, infA, rps19, ndhF, rpl32, ndhD, ndhI, and $y c f 1$. Non-coding regions that were most variable were matK-rps16, petN-psbD, ndhC-trnV-UAC, rbcL-psaI, psbE-petL, and rpl14-ycf1. These regions of maximum variability will no doubt prove the most informative for phylogenetic studies in the Juglandaceae [6, 12]. Previous studies have identified rpl22, rps 19 and $y c f 1$ genes as the most variable genes in the Juglandaceae plastomes based on high indel density [12]. It was surprising, however, that the LSC region also contained variation, including 2577 bp differences among Juglandaceae plastomes, while SSC had 237 bp and IR had 296 bp differences among plastomes (Table 1). The identification of these regions of variability in protein-coding genes (CDS) and intergenic spacer (IGS) regions will be useful for the study of the evolution, phylogeny, biogeography of the walnut family (Juglandaceae) and Fagales [4, 27-29, 34, 35 ] and, potentially, for DNA barcoding. Three potential pseudogenes (infA, rpl22, and $y c f 15$ ) will also be valuable genetic resource for study of plastid transfer to the nucleus and for studies of the evolution of the walnut family and Fagales [10, 20].

\section{Backbone relationship of Juglandaceae}

The phylogeny of the Juglandaceae has been inferred based on microsporogenesis, morphology [22, 23], fossils [24, 27, 49], molecular markers [36-38], and combined data (morphology, fossils, and molecular data) $[16,27]$. Several recent studies of phylogeny in the Juglandaceae have included data from plastomes [12, 36-39,
50-52]. The previously recognized subfamilies (Engelhardioideae and Juglandoideae), tribes (Platycaryeae and Juglandeae) and subtribes (Caryinae and Juglandinae) were all strongly supported [27, 31, 36-39]. Our phylogenetic analyses indicated that the Juglandaceae is subdivided into three major clades corresponding to the three subfamilies Rhoipteleoideae, Engelhardioideae, and Juglandoideae [17, 27, 28, 30, 35, 36, 51] (Fig. 1). The evidence for these three subfamilies can be found from morphology, fossil, and molecular data [17], fruits [23], and flower development [23]. The subfamily Engelhardioideae includes Engelhardia, Oreomunnea, and Alfaroa [23] (Fig. 1). Our results also supported the separation of Alfaropsis [17, 27] as a separate genus within Engelhardioideae (Additional file 4: Fig. S3). The Rhoipteleoideae (Rhoiptelea chiliantha) was a basal, monophyletic branch, which indicated that winged (dry) fruit was an ancestral character for the Juglandaceae (Fig. 3). The fruits of Myricaceae, the closest relative of the Juglandaceae, are small and fleshy, of a type common among Cretaceous flora [35-39]. The subfamily Rhoipteleoideae has only one species (Rhoiptelea chiliantha), which is a threatened and endemic in China [36-39, 43].

The subfamily Juglandoideae includes the commercially important nut-producing trees commonly called walnuts and butternuts (Juglans), pecan and hickory (Carya) [15, 27, 30, 36] (Fig. 1). The Persian walnut, Juglans regia, is one of the major nut crops of the world. Walnuts and hickories are also valuable timber trees [53]. Our plastid phylogenomic analyses fully resolved relationships among the major clades and genera of Juglandoideae (Fig. 3). Within subfamily Juglandoideae, four tribes are recognized (Juglandeae, Cyclocaryae, Platycaryae, and Hicorieae). Based on whole chloroplast genomes and sixteen mtCDS, the phylogenetic trees results strongly supported the previously published merger of the genera Annamocarya and Carya into the genus Carya (Fig. 3) [16, 27, 35-38]. Five genera, with their subgenera and sections were identified previously [24, 25, 27], i.e., Carya (here including Annamocarya), Platycarya, Cyclocarya, Pterocarya, and Juglans. These five genera resolved in our analysis with $100 \%$ support (Fig. 3). The phylogenetic relationships of the genera of the Juglandaceae reveal that Carya retains more primitive characters than Platycarya based on chloroplast DNA variation and morphology [54].

In previous studies, it was suggested the genus Cyclocarya is sister to genus Platycarya [17] based on fossil, chloroplast DNA fragments, and morphological data. Our data confirm this relationship (Figs. 3 and 4). Alternatively, it was suggested by Xiang et al. (2014) that Platycarya is sister to Juglans based on five chloroplast markers [31], and that Carya and Platycarya are sister 
groups [31]. Others considered Cyclocarya and Juglans to be sister groups [29]. Within Juglandoideae, our results strongly supported five genera (Juglans, Pterocarya, Cyclocarya, Platycarya, Carya) based on our chloroplast data (Fig. 3a), which is consistent with the phylogeny inferred from RAD-Seq data [36]. Using criteria based on fruit morphology, however, Carya and Juglans are sister groups [35], this relationship was not confirmed by our DNA-based analysis (Fig. 4), and Cyclocarya and Pterocarya are sister groups, a relationship supported in our data (Figs. 3 and 4) [35]. Previously, Smith and Doyle (1995) [54], based on chloroplast DNA and morphological data, concluded that Platycarya evolved earlier than Carya; our results based on nuclear resequencing (Fig. 3c) supported this conclusion. Our results based on sequencing the entire chloroplasts, however, indicated that the differentiation of Carya preceded Platycarya (Figs. 3 and 4; Additional file 4: Fig. S3), as suggested by Zhang et al. (2013) [30], although their differentiation, about 57 Mya, was roughly simultaneous. Many previous studies of Juglandaceae have suggested frequent hybridizations between species, which can prevent establishing conclusive taxonomies and bias the estimation of species divergence time. For instance, Zhang et al. (2019) [32] used whole genomic resequencing data to infer phylogenetic relationships and discover hybrid origins of species in Juglans [32]. Zhao et al. (2018) inferred walnut hybridized with a distinct lineage of $J$. mandshurica to form $J$. hopeiensis, a controversial taxon that results from phylogenomic and population genetic analyses, transcriptomics, Genotyping-By-Sequencing, and whole chloroplast genome data indicated is a horticultural variety [55].

\section{The phylogenetic relationships within genera of Juglandaceae}

The phylogenetic relationships within genera of Juglandaceae were resolved partly in recent papers [27, 36-38], however, the species delimitations in Carya, Pterocarya, and Juglans remain a subject of debate. The generic circumscription of Annamocarya (also C. sinensis) has frequently been altered, and many genera have been segregated from or merged with Carya [27, 36, 37, 51, 56]. Our analyses fully supported some previously suggested intrageneric relationships, and added additional evidence supporting some of the recently altered generic circumscriptions based on analyses with more appropriate representation at the species level (Fig. 3; Additional file 4: Fig. S3) [27, 36-38]. Placement of the species C. sinensis (Chinese Hickory, beaked walnut, or beaked hickory) into Carya (Fig. 3; Additional file 4: Fig. S3) was well attested [27, 36, 37].

Species diversity centers of the genus Pterocarya occur in the northern temperate zone [27, 36, 37]. The previously unresolved intrageneric relationships of Pterocarya were resolved with high support using chloroplast genome data. P. stenoptera, P. hupehensis, and P. tonkinensis were clustered as a group (Fig. 3a); a second group consisted of P. macroptera and P. fraxinifolia (Fig. 3a) [37]. Morphology of the two groups within Pterocarya differs: group one species (P. stenoptera, $P$. hupehensis, and $P$. tonkinensis) have naked terminal buds, while the group two species $P$. macroptera and P. fraxinifolia have terminal buds with 2 to 4 caducous scales $[37,57]$. We consider these taxa species relationships based on our chloroplast genome, mtDNA fragments, and nuclear SNPs data (Fig. 3, but see Fig. 4), however we did not complete a detailed phylogeny of Pterocarya because our sample pool was too small.

Our phylogenomic analyses resolved Juglans into three clear sections (Cardiocaryon, Dioscaryon, and Rhysocaryon) with high support (Fig. 3). Earlier phylogenies [22, 24] based on limited molecular data sometimes included a fourth section (Trachycaryon) containing only the North American species J. cinerea. The separation of Trachycaryon as distinct from section Cardiocaryon was inconsistent with morphology [21-24] and nuclear markers [15, 58], but congruent with fossil data [24] and the results of other analyses based on plastid sequences [12, 15]. In our phylogenetic analysis of nuclear genome SNPs, American butternut (J. cinerea) has high support $(100 \%)$ as sister to Section Cardiocaryon (Asian butternut, J. cathayensis, J. mandshurica, and J. ailantifolia) (Fig. 3c).

Based on sequence data from $16 \mathrm{mtCDS}$ and 61 chloroplast protein-coding genes, our results supported the unification of J. mandshurica, J. ailantifolia, and J. cathayensis within sect. Cardiocaryon (Fig. 3b; Additional file 4: Fig. S3), consistent with a previous conclusion based on genotyping by sequencing data $[22,55]$. We also confirmed that the Ma walnut (J. hopeiensis) arose from the resent hybridization of $J$. regia and $J$. mandshurica based on both matrilineal and biparental inheritance data (Fig. 3) [12, 55]. The placement of $J$. cinerea into Rhysocaryon (black walnuts) based on plastome sequence was clear (Fig. 3a), however, it belongs to Cardiocaryon (Asian butternuts) based on nuclear sequences (Fig. 3c), and its morphology is consistent with Cardiocaryon $[12,15]$. In addition, J. cinerea can hybridize with members of Cardiocaryon and even Dioscaryon, but not with Rhysocaryon [59]. All other North American Rhysocaryon freely hybridize. The discordance between the J. cinerea nuclear genome and its plastome is almost certainly the result of a chloroplast capture [16, 32]. It is notable that the chloroplast of $J$. cinerea is not an ancient one (ancestral to the Rhysocaryon) but is instead most like J. nigra (Figs. 3 and 4). 
Our results indicated that the capture of a Rhysocaryon chloroplast by $J$. cinerea capture was relatively recent (Figs. 3 and 4). Hybridization and chloroplast capture between Rhysocaryon and Cardiocaryon apparently played a major role in the diversification of Juglans, as it did in other plant families [33, 36-38, 60]. The evaluation of divergence time using strictly bifurcating tree methods can be misleading because gene flow can result in underestimates of species divergence time [61].

\section{Dating the origin and historical diversification of Juglandaceae}

Stem ages in the Juglandaceae are controversial $[13,17$, 29, 30]. Most previous studies estimated a stem age of Juglandaceae about 84 Mya in the Cretaceous [25, 29], however, the divergence times for some genera remain uncertain $[29,30]$, as only a few studies have examined the divergence times of the major genera and within the species of the family $[17,30]$. The lack of a robust phylogenetic framework and time tree has hindered development of a full understanding of the diversification of Juglandaceae.

The crown ages of Betulaceae, Myricaceae, and Casuarinaceae were 74.0 Mya (66.9-80.3), 90.4 Mya (85.0-94.6), and $82.8 \mathrm{Mya}$ (74.7-88.6), respectively [31]. Estimates of the crown age of Juglandaceae varied among previous studies, 78 Mya by Manos et al. (2007) [17], 71 Mya by Larson-Johnson (2016) [36], 85.5 Mya by Sauquet et al. (2012) [29], 81.4 Mya by Mu et al. (2020) [36], 105 Mya by Zhang et al. (2021) [27], and 79.9 Mya by Xiang et al. (2014) [31]. Our results indicated the stem age of Juglandaceae to be during the late Cretaceous (78.58 Mya with 95\% HPD: 76.58-80.50 Mya). The major diversification of the family is recorded in the pollen and megafossil record of the early Tertiary ( 65.0 Mya) at the K-T boundary. The three subfamilies diverged during the Late Cretaceous to Early Palaeocene (60.7-68.6 Mya) (Figs. 3 and 4). Our estimates of divergence times among subfamilies and major genera were from 50.9 to $62.0 \mathrm{Mya}$ in warm and dry habitats during the Middle Palaeocene to the Early Eocene (Fig. 4), which is largely consistent with the estimates of Xiang et al. (2014) [31], Larson-Johnson (2016) [35], and Zhang et al. (2021) based on fossil, morphological, molecular, and (paleo) environmental data [27]. We estimated the divergence time of Juglans and Pterocarya to have been $\sim 47$ Mya (Fig. 4; Manos et al. 2007, $\sim 55$ Mya) [17]; Pterocarya and Cyclocarya diverged $~ 56$ Mya (Fig. 4; Manos et al. 2007, 59 Mya [17], Zhang et al. 2021, 50 Mya [27], and Mu et al. 2020, 60 Mya [36]). Three groups [Xiang et al. (2014), Larson-Johnson (2016), and Song et al. (2020)] estimated a divergence time between Juglans and Pterocarya of $\sim 24$ Mya [31, 35, 37], and 18 Mya between Pterocarya and Cyclocarya [35]. By the end of the Eocene, Cyclocarya and Platycarya became extinct in North America but survived in Eurasia [25]. Our results indicated Carya emerged as an animaldispersed genus about 58 Mya, considerably earlier than the estimate ( 44 Mya) of Larson-Johnson (2016) [35] and Song et al. (2020, $40 \mathrm{Mya}$ ) [37], but later than the estimate ( $80 \mathrm{Mya})$ of Zhang et al. (2021) [27], although we agree that the overwhelming majority of winged and wingless fruited genera diverged or diversified during the Paleogene, probably reflecting adaptation to changing regeneration regimes [62]. We estimated the divergence time between the Juglandoideae and Engelhardioideae, which are reciprocal monophyly subfamilies, was $\sim 68.6$ Mya, later than the estimate of $\mathrm{Mu}$ et al. (2020) was $\sim 79.18$ Mya [36].

From the early Tertiary to the Neogene there was likely extensive migration and exchange among North Atlantic, North America, western European, and Asian flora [25]. Interestingly, most species within the extant genera diversified between 18.5 and 8.5 Mya in warm and dry environments of the Early Miocene (Fig. 4), a period of especially rapid speciation within Juglans and Pterocarya. Juglandaceae species diversity in from Oligocene to Pliocene with a rapid increase elucidated by Zhang et al. 2021 (between 30 and 5 Mya) [27], Mu et al. 2020 (between 20 and 5 Mya) [36], and Song et al. 2020 (between 13 and 5 Mya) [37]. Some closely related taxa within Juglans appear to have diverged relatively recently, under the influence of climate change during the Quaternary glacial period (Fig. 4; Bai et al. 2017) [63]. For example, J. regia and J. sigillata, J. mandshurica and J. hopeiensis, and Carya hunanesis and C. kweichwensis (Fig. 4). Overall, the Juglandaceae reflect a complex evolutionary history and diversification affected by changes in geography, distinctive distributions, climate changes, coevolution with animals. Biotic interactions (e.g., pathogens) no doubt also had a role in driving species abundance and distribution [63], but biotic interactions of that type are difficult to detect from current data [36-39].

\section{Conclusions}

Our results are a first attempt to use whole genomes to elucidate the characterize sequence divergence and evolutionary history in the Juglandaceae. Evidence of early lineage diversification, hybridization and extinction lead us to predict complex evolutionary histories for the extant species in the Juglandaceae. A fully resolved, strongly supported, time-calibrated phylogenetic tree of Juglandaceae will provide an important framework for studying classification, diversification, biogeography, phenotypic evolution, gene function and comparative genomics of this important family. Our 
results supported some recently clarified circumscriptions of controversial genera, although our taxonomic sampling is insufficient to stand alone as definitive. Variation within our newly annotated whole chloroplast genomic sequences (available in GenBank) should be a useful resource for study of the evolution, for DNA barcoding, phylogeny, biogeography, and studies of genetic variation in the walnut family (Juglandaceae). Wider plastid phylogenomics, whole genomes (nuclear data), a more complete fossil record, better dating of the fossil record, and more studies of morphology will all be needed to fully reconstruct the phylogeny of woody plant families such as the Juglandaceae and other families of Fagales.

\section{Methods}

Taxon sampling, genomic DNA extractions, library, and sequencing

We analyzed 27 species of Juglandaceae from seven genera that span the taxonomic, geographic, and morphological range of the family. These were contextualized using published plastomes of nine species of Fagales (include four species for Betulaceae, and five species for Fagaceae), three species of Cucurbitales, and four species of Rosales (Additional file 1: Table S1). The voucher specimens were deposited in the herbarium of Key Laboratory of Resource Biology and Biotechnology in Western China (Ministry of Education), Northwest University (Table 1). We collected fresh leaf samples from the field, and the samples were stored in air tight bags filled with silica gel desiccant for later DNA extraction.

Total genomic DNA was extracted from $200 \mathrm{mg}$ of silica gel-dried leaves using a modified CTAB (cetrimonium bromide) method [64, 65]. The DNA concentration was quantified using a NanoDrop spectrophotometer (Thermo Scientific, Carlsbad, CA, USA). A paired-end (PE) library with $350 \mathrm{bp}$ insert size was constructed using the Illumina PE DNA library kit according to the manufacturer's instructions and sequenced using an Illumina Hiseq2500 by Novogene (www.novogene.com, China).

\section{Mitochondrion protein-coding genes (mtCDS) primer design and PCR amplification}

We investigated genetic variation within mitochondrial protein-coding genes (mtCDS) to evaluate phylogenetic relationships of the Juglandaceae. We used a total of sixteen primers designed from the complete mitochondrion sequence of Populus tremula (NCBI accession number: KT337313.1) using Primer3 (Sangon Biotech in Shanghai, China). Primers were targeted to the sequence of mitochondrial protein-coding genes of $P$. tremula (Additional file 1: Table S5). PCR amplification was carried out on a SimpliAmp Thermal Cycler (Applied Biosystem, USA) in $20 \mu \mathrm{L}$ reaction volumes $(10 \mu \mathrm{L} 2 \times$ PCR Master Mix including $0.1 \mathrm{U}$ Taq polymerase $/ \mu \mathrm{L} ; 500$ $\mu \mathrm{M}$ each dNTP; 20 mMTris- $\mathrm{HCl}$ (pH8.3); $100 \mathrm{mMKCl}$; $3.0 \mathrm{mM} \mathrm{MgCl}{ }_{2}$ (Tiangen, Beijing, China), $0.5 \mu \mathrm{L}$ each primer, $2 \mu \mathrm{L} \mathrm{BSA}, 2 \mu \mathrm{L}$ of $10 \mathrm{ng} / \mu \mathrm{L}$ DNA). The PCR was programmed for $3 \mathrm{~min}$ at $94{ }^{\circ} \mathrm{C}$ followed by 35 cycles of $15 \mathrm{~s}$ at $93{ }^{\circ} \mathrm{C}, 1 \mathrm{~min}$ at annealing temperature (Additional file 1: Table S5), $30 \mathrm{~s}$ at $72{ }^{\circ} \mathrm{C}$ and extension of $10 \mathrm{~min}$ at $72{ }^{\circ} \mathrm{C}$. After PCR amplification, fragments were sequenced by Sangon Biotech (Shanghai, China).

\section{Plastomes assembly and annotation}

The sequenced and assembled plastomes were quality controlled using the NGSQC toolkit v2.3.3 trim tool to remove low quality reads, unknown bases, adapter sequences, and sequencing errors [66]. Short reads were assembled into long contigs using SPAdes Genomic Assembler v3.6.0 [67], followed by manual checking and finishing. We used a reference $J$. regia complete chloroplast genome (Genbank accession number KT963008) in this study [50]. The contigs were assembled in Geneious v8.0.2 [68]. To exclude nuclear DNA, we used BLAST to remove contigs that did not align to a reference plastome from J. regia [50]. A reference-based assembly allowed us to reconstruct each of all other species [13].

After we identified the boundaries between the inverted repeats (IR) and the single copy regions, i.e., the Large Single Copy (LSC) and Small Single Copy (SSC) regions, the completed plastomes were annotated using the online software DOGMA based on the J. regia reference [50, 68, $69]$. We manually annotated start and stop codons and other regions of interest using Geneious v8.0.2 [50]. A circular representation of each plastome was visualized in OGDraw [70]. Finally, gene content, order, and variability were analyzed in Geneious and R [71]. The plastid genomes data were deposited in National Center for Biotechnology Information (NCBI), the accession numbers were KX703001 to KX703038 (Table 1).

\section{Variant calling}

Using paired-end $(2 \times 150 \mathrm{bp})$ Illumina sequencing, we obtained high sequencing depth $(>30 \times)$ per sample based on alignment with the J. regia reference plastome [50]. After aligning the re-sequenced reads, we processed the alignments to remove duplicate reads and applied a series of quality control filters with the intent of limiting false-positive variants. Sequence reads passing Illumina's quality control filter were aligned using bwa-mem algorithm of BWA v0.7.12 [72] and then mapped to the $J$. 
regia plastid genome. Only uniquely mapped reads were retained, which removed the repeat region IR. Duplicate reads were removed from individual sample alignments using Picard tools v2.5.0 (https://github.com/broadinsti tute/picard) Mark Duplicates function and assigned genomic positions for each accession based on the alignment files generated by SAMtools v0.1.19 [73].

The SNPs (single nucleotide polymorphisms) and small Indels (insertion-deletion) among Juglandaceae plastid genome accessions were identified if they were supported by at least three mapped reads. Following bwa-mem mapping, the rest of the sequencing pipeline was performed using the toolkit GATK v3.5.0 [74]. Reads present in areas surrounding Indels were realigned using the built-in function Indel Realigner, after which SNPs were called using Unified Genotyper. Finally, a series of quality filters were applied to reduce systematic errors, including quality-by-depth ratio (QD) $<10$, ReadPosRankSum < -8.0 , depth coverage (DP) $\geq 30$, probability of strand bias (FS) $>10.0$, SNPs that passed these filters were kept for subsequent analyses. Finally, we use the stats module in the bcftools v1.1 to count SNPs and Indels and calculate $\mathrm{Ts} / \mathrm{Tv}$ (transition/transversion) rates [75].

In this study, we called the nuclear SNPs from all samples of Juglandaceae (Additional file 1: Table S3). The Illumina paired-end reads from each sample were first processed to remove adaptor and low-quality sequences using Trimmomatic [76]. The cleaned unique reads were aligned to the common walnut reference genome version 1.0 (https://treegenesdb.org/FTP/Genomes/Jure/) using BWA [46, 73], and only uniquely mapped reads were retained. Following mapping, genotypes were assigned to each genomic position for each sample based on the alignment files generated by SAMtools [72]. Single nucleotide polymorphism (SNPs) and small indels (insertion and deletion) in the 27 samples were identified using GATK [74]. The redundant reads were then filtered based on the location of clean reads in the reference genome using software Picard (Picard: http://sourc eforge.net/projects/picard/). We used GATK's Haploype Caller (local haplotype assembly) algorithm for SNPs and InDels based on each sample.

\section{Partition strategy and phylogenetic analysis}

To infer the evolutionary relationships among the 27 Juglandaceae plastomes, and to test the phylogenetic signal from different regions of the plastomes, we reconstructed the Juglandaceae phylogeny using the following four datasets based on the exons of protein-coding genes, whole chloroplast genome data, mitochondrial proteincoding genes (mtCDS), whole genome re-sequencing of nuclear genome SNPs (nrSNPs), and ITS (Internal transcribed spacers) sequences; to avoid large amounts of missing data in the phylogenetic analyses, sixty-one protein coding genes that were shared by all 44 taxa were extracted and aligned (Additional file 1: Table S4). Bestfit partitioning schemes and models were selected using the greedy search mode implemented in PartitionFinder v2.1.1 [77] (Additional file 1: Table S6).

Plastomes were aligned using default settings in MAFFT v7.245 [78]. The resulting alignments were manually checked in Geneious v8.0.2 [50]. The best-fit nucleotide substitution model for all our plastome data sets was determined (as suggested by Modeltest v3.7 with the Akaike information criterion (AIC) [79, 80]. A concatenated data set was analyzed using Bayesian Inference (BI) and Maximum Likelihood (ML) analysis in MrBayes v3.2.6 [53] or RAxML v8.1.24 [81]. BI trees were produced by MrBayes v3.2.6 set at 10,000,000 generations. Two independent Markov chain Monte Carlo (MCMC) chains were run, each with one cold chain and three incrementally heated chains. Trees were sampled every 10,000 generations, with the first $25 \%$ of the trees discarded as burn-in. Stationarity was considered reached when the average standard deviation of split frequencies was $<0.01$. The Maximum Likelihood (ML) trees were generated using RAxML v8.1.24 using a GTRGAMMA model [81]. For ML analysis, difference general time reversible models were performed with all data sets. For all analyses, 10 independent ML searches were conducted, bootstrap support was estimated with 1000 bootstrap replicates, and bootstrap (BS) proportions were drawn on the tree with highest likelihood score from the 10 independent searches. We generated multiple mtCDS sequence alignments using ClustalX with default parameters [82]. The phylogenetic tree analysis was performed using MEGA7 [83].

For the phylogenetic tree analysis based on nuclear genome data, we selected a total of 1,161,468 SNPs with minor allele frequency (MAF) $\geq 5 \%$ and missing rate per site $\leq 10 \%$ for phylogenetic analyses. A Maximum Likelihood (ML) tree was constructed using RAxML v8.1.24 in 1000 bootstrap replicates [81]. To gain a better understanding of the species relationships, we selected 55 species to represent all extant genera in the Juglandaceae for which internal transcribed spacer (ITS) sequence data are available in NCBI (Additional file 1: Table S7). We generated multiple ITS sequence alignments using ClustalX with default parameters [82], and a phylogenetic tree analysis using Maximum Likelihood analysis [81].

\section{Divergence-time estimation and fossil calibration}

We estimated the divergence time of Juglandaceae species based on complete chloroplast genome data combined with six fossil calibrations (Additional file 1: Table S8) [24, 25, 29]. Penalized likelihood (PL) dating 
analyses were conducted using the treePL v1.0 program [84]. To identify the appropriate level of rate heterogeneity in the phylogram, a data-driven cross-validation analysis was conducted with treePL v1.0. One thousand bootstrap replicates with branch lengths were also generated using RAxML v8.1.24 for calculating the confidence age intervals with TreeAnnotator as implemented in BEAST v2.4.5 with a GTR + I + G substitution model and an uncorrelated lognormal relaxed-clock $[85,86]$. The phylogenetic trees were then compiled into a maximum clade credibility tree using Tree Annotator v1.8.0 [87]. The program FigTree v1.3.1 (http://tree.bio.ed.ac.uk) was used to visualize mean node ages and highest posterior density (HPD) intervals at 95\% (upper and lower) for each node and to estimate branch lengths and divergence times.

\section{Supplementary Information}

The online version contains supplementary material available at https://doi. org/10.1186/s12862-021-01917-3.

Additional file 1: Table S1. The taxa, Genbank accession number, and family of 41 species used for phylogenetic analysis. Table S2. Characterization of three primers to verified three pseudogenes. Table S3. Summary of variants from all Juglandaceae genome resequencing based on comparison with Juglans regia whole genome sequences. Table S4. Protein-coding genes $(n=61)$ included in the phylogenetic analysis. Table S5. Characterization of sixteen mitochondrion protein-coding genes (mtCDS) primers used in this study. Table S6. The PartitionFinder method for the best model combinations of the ML phylogenetic tree based on 61 protein-coding genes. Table S7. Sources of Internal transcribed spacer (ITS) sequences used in this study. Table S8. Fossil evidence used for estimation divergence time of Juglandaceae.

Additional file 2: Fig. S1. Alignment of three pseudogenes in the all Juglandaceae species and five eudicot outgroup plastomes. (a) infA. (b) rp/22, and (c) ycf15. The black box with an asterisk represents stop codons. (d) The PCR amplication products of three pseudogenes. Their identity was verfied by Sanger sequencing (primers see Table S8). (e) The amino acid sequence of three pseudogenes of ten species of the Juglandaceae.

Additional file 3: Fig. S2. The properly mapped ratio (red line) and heterozygosity ratio (blue line) of whole genome sequence data from Juglandaceae. All comparisons are to Juglans regia.

Additional file 4: Fig. S3. The Maximum Likelihood (ML) phylogenetic tree of 55 Juglandaceae species based on ITS (Internal transcribed spacers) sequences inferred by RAxML. Data from NCBI, see Additional file 1: Table S6 for details. Numbers at nodes correspond to ML bootstrap percentages (10,000 replicates). The three subfamilies of the Juglandaceae are indicated with shading: Rhoipteleoideae [grey (C)], Engelhardioideae [red (B)], and Juglandoideae [blue (A)] are shown.

\section{Acknowledgements}

We thank N. Hou, Y. L. Xu, N. Lin and L. Wang for assisting with taxon sampling. Mention of a trademark, proprietary product, or vendor does not constitute a guarantee or warranty of the product by the U.S. Department of Agriculture and does not imply its approval to the exclusion of other products or vendors that also may be suitable.

\section{Authors' contributions}

$\mathrm{PZ}, \mathrm{HZ}$, and $\mathrm{KW}$ designed and managed the project; $\mathrm{HZ}, \mathrm{YH}, \mathrm{AE}, \mathrm{PL}$, and $\mathrm{PZ}$ collected the materials; $\mathrm{HZ}, \mathrm{YH}, \mathrm{PZ}$, and $\mathrm{KW}$ prepared and purified DNA samples; $\mathrm{HZ}, \mathrm{PZ}, \mathrm{PL}, \mathrm{YH}$, and KW performed the data analyses; $\mathrm{PZ}$ wrote the paper; $\mathrm{HZ}$,
$\mathrm{KW}, \mathrm{SZ}$, and FZ revised the paper. All authors read and approved the final manuscript.

\section{Funding}

This work was supported by the National Natural Science Foundation of China (32070372; 41471038; 31200500), the Natural Science Foundation of Shaanxi Province of China (2019JM-008), and in part by the United States Department of Agriculture, Forest Service.

\section{Availability of data and materials}

The annotated newly chloroplast genomic sequence were deposited into GenBank (MH188288-MH188304, MH189594-MH189595; Details see Table 1).

\section{Declarations}

Ethics approval and consent to participate

Not applicable.

\section{Consent for publication}

Not applicable.

\section{Competing interests}

The authors declare that they have no competing interests.

\section{Author details}

${ }^{1}$ College of Forestry, Northwest A\&F University, Yangling 712100, Shaanxi, China. ${ }^{2}$ Key Laboratory of Resource Biology and Biotechnology in Western China, Ministry of Education, College of Life Sciences, Northwest University, Xi'an 710069, Shaanxi, China. ${ }^{3}$ USDA Forest Service Hardwood Tree Improvement and Regeneration Center (HTIRC), Department of Forestry and Natural Resources, Purdue University, 715 West State Street, West Lafayette 47907, Indiana, USA.

Received: 7 May 2021 Accepted: 22 September 2021

Published online: 21 October 2021

\section{References}

1. Daniell H, Lin CS, Yu M, Chang WJ. Chloroplast genomes: diversity, evolution, and applications in genetic engineering. Genome Biol. 2016;17:134.

2. Huang CH, Sun R, Hu Y, Zeng L, Zhang N, Cai L, Zhang Q, Koch MA, Al-Shehbaz I, Edger PP, et al. Resolution of Brassicaceae phylogeny using nuclear genes uncovers nested radiations and supports convergent morphological evolution. Mol Biol Evol. 2016;33:394-412.

3. Weng ML, Ruhlman TA, Jansen RK. Expansion of inverted repeat does not decrease substitution rates in Pelargonium plastid genomes. New Phytol. 2017:214:842-51

4. Yang YY, Qu XJ, Zhang R, Stull GW, Yi TS. Phylogenetic relationships in Chinese oaks (Fagaceae, Quercus): evidence from plastid genome using low-coverage whole genome sequencing. Genomics. 2021;113:1438-47.

5. Cai $X L$, Landis JB, Wang HX, Wang JH, Zhu ZX, Wang HF. Plastome structure and phylogenetic relationships of Styracaceae (Ericales). BMC Ecol Evo. 2021;21:103.

6. Song Y, Yu WB, Tan Y, Liu B, Yao X, Jin J, Padmanaba M, Yang JB, Corlett RT. Evolutionary comparisons of the chloroplast genome in Lauraceae and insights into loss events in the Magnoliids. Genome Biol Evol. 2017:9:2354-64.

7. Uribe-Convers S, Carlsen MM, Lagomarsino LP, Muchhala N. Phylogenetic relationships of Burmeistera (Campanulaceae: Lobelioideae): combining whole plastome with targeted loci data in a recent radiation. Mol Phylogenet Evol. 2017;107:551-63.

8. Zhang SD, Jin JJ, Chen SY, Chase MW, Soltis DE, Li HT, Yang JB, Li DZ, Yi TS. Diversification of Rosaceae since the Late Cretaceous based on plastid phylogenomics. New Phytol. 2017;214:1355-67.

9. Peng J, Zhao Y, Dong M, Liu S, Hu Z, Zhong X, Xu Z. Exploring the evolutionary characteristics between cultivated tea and its wild relatives using complete chloroplast genomes. BMC Ecol Evo. 2021:21:71.

10. Jansen RK, Saski C, Lee SB, Hansen AK, Daniell H. Complete plastid genome sequences of three Rosids (Castanea, Prunus, Theobroma): 
evidence for at least two independent transfers of rpl22 to the nucleus. Mol Biol Evol. 2011;28:835-47.

11. Liu Q, Li X, Li M, Xu W, Schwarzacher T, Heslop-Harrison JS. Comparative chloroplast genome analyses of Avena: insights into evolutionary dynamics and phylogeny. BMC Plant Biol. 2020;20:406.

12. Ma T, Wang K, Hua Q, Xia Z, Wan D, Wang Q, Feng J, Jiang D, Ahanic H, Abbottd RJ, et al. Ancient polymorphisms and divergence hitchhiking contribute to genomic islands of divergence within a poplar species complex. P Natl Acad Sci USA. 2018;115:E236-43.

13. Dong W, Xu C, Li W, Xie X, Lu Y, Liu Y, Jin X, Suo Z. Phylogenetic resolution in Juglans based on complete chloroplast genomes and nuclear DNA sequences. Front. Plant Sci. 2017;8:1148.

14. Hu YH, Woeste KE, Zhao P. Completion of the chloroplast genomes of five Chinese Juglans and their contribution to chloroplast phylogeny. Front Plant Sci. 2017;7:1955

15. Stanford AM, Harden R, Parks CR. Phylogeny and biogeography of Juglans (Juglandaceae) based on matK and ITS sequence data. Am J Bot. 2000;87:872-82.

16. Aradhya MK, Potter D, Gao F, Simon CJ. Molecular phylogeny of Juglans (Juglandaceae): a biogeographic perspective. Tree Genet Genomes. 2007:3:363-78.

17. Manos PS, Soltis PS, Soltis DE, Manchester SR, Oh SH, Bell CD, Dilcher DL, Stone DE. Phylogeny of extant and fossil Juglandaceae inferred from the integration of molecular and morphological data sets. Syst Biol. 2007;56:412-30.

18. Chen Z, Grover CE, Li P, Wang Y, Nie H, Zhao Y, Wang M, Liu F, Zhou Z, Wang $X$, et al. Molecular evolution of the plastid genome during diversification of the cotton genus. Mol Phylogenet Evol. 2017;112:268.

19. Bernhardt N, Brassac J, Kilian B, Blattner FR. Dated tribe-wide whole chloroplast genome phylogeny indicates recurrent hybridizations within Triticeae. BMC Evol Biol. 2017:17:141.

20. Zhou H, Gao X, Woeste K, Zhao P, Zhang S. Comparative analysis of the complete chloroplast genomes of four chestnut species (Castanea). Forests. 2021;21:861.

21. Lu AM. On the geographical distribution of the Juglandaceae. Acta Phytotaxon Sin. 1982;20:257-74.

22. Lu AM, Stone DE, Grauke LJ. Juglandaceae. In: Wu ZY, Raven PH, Hong DY, editors. Flora of China. Beijing: Science Press \& Missouri Botanical Garden Press, 1999; p. 277-285.

23. Manning WE. The morphology of the flowers of the Juglandaceae. I. The inflorescence. Am J Bot. 1938;25:407-19.

24. Manning WE. The classification within the Juglandaceae. Ann Mo Bot Gard. 1978;65:1058-87.

25. Manchester SR, Garden MB. The fossil history of the Juglandaceae. Ann Mo Bot Gard. 1987;21:1-137.

26. Guo W, Chen J, Li J, Huang J, Wang Z, Lim KJ. Portal of Juglandaceae: a comprehensive platform for Juglandaceae study. Hortic Res. 2020;7:35.

27. Zhang Q, Ree RH, Salamin N, Xing Y, Silvestro D. Fossil-informed models reveal a boreotropical origin and divergent evolutionary trajectories in the walnut family (Juglandaceae). Syst Biol. 2021. https://doi.org/10.1093/ sysbio/syab030.

28. Angiosperm Phylogeny Group (APG IV). An update of the Angiosperm Phylogeny Group classification for the orders and families of flowering plants: APG IV. Bot J Linn Soc. 2016;181:1-20.

29. Sauquet H, Ho SY, Gandolfo MA, Jordan GJ, Wilf P, Cantrill DJ, Bayly MJ, Bromham L, Brown GK, Carpenter RJ. Testing the impact of calibration on molecular divergence times using a fossil-rich group: the case of Nothofagus (Fagales). Syst Biol. 2012;61:289-313.

30. Zhang JB, Li RQ, Xiang XG, Manchester SR, Lin L, Wang W, Wen J, Chen ZD. Integrated fossil and molecular data reveal the biogeographic diversification of the eastern Asian-eastern North American disjunct hickory genus (Carya Nutt.). PLoS One. 2013;8:e70449.

31. Xiang XG, Wang W, Li RQ, Lin L, Liu Y, Zhou ZK, Li ZY, Chen ZD. Large-scale phylogenetic analyses reveal Fagalean diversification promoted by the interplay of diaspores and environments in the Paleogene. Perspect Plant Ecol. 2014;16:101-10.

32. Zhang BW, Xu LL, Li N, Yan PC, Jiang XH, Woeste KE, Lin K, et al. Phylogenomics reveals an ancient hybrid origin of the Persian walnut. Mol Biol Evol. 2049;11:2451-61.

33. Zhang JP, Zhang WT, Ji FY, Qiu J, Song XB, Bu DC, Pan G, Ma QG, Chen JX, Huang RM, Chang YY, Pei D. High-quality walnut genome assembly reveals extensive gene expression divergences after whole-genome duplication. Plant Biotechnol J. 2020;18:1848-50.

34. Li RQ, Chen ZD, Lu AM, Soltis DE, Soltis PS, Manos PS. Phylogenetic relationships in Fagales based on DNA sequences from three genomes. Int J Plant Sci. 2004;165:311-24.

35. Larson-Johnson K. Phylogenetic investigation of the complex evolutionary history of dispersal mode and diversification rates across living and fossil Fagales. New Phytol. 2016;209:418-35.

36. Mu XY, Tong L, Sun M, Zhu YX, Wen J, Lin QW, Liu B. Phylogeny and divergence time estimation of the walnut family (Juglandaceae) based on nuclear RAD-Seq and chloroplast genome data. Mol Phylogenet Evol. 2020;147:106802.

37. Song $Y G$, Fragnière $Y$, Meng HH, Li Y, Bétrisey $S$, Corrales $A$, Manchester S, Deng M, Jasińska AK, Sâm HV, Kozlowski G. Global biogeographic synthesis and priority conservation regions of the relict tree family Juglandaceae. J Biogeog. 2020;47:643-57.

38. Song YG, Li Y, Meng HH, Fragnière $Y$, Ge BJ, Sakio H, Yousefzadeh $H$, Bétrisey S, Kozlowski G. Phylogeny, taxonomy, and biogeography of Pterocarya (Juglandaceae). Plants. 2020;9:1524.

39. Zhang CY, Low SL, Song YG, Nurainas, Kozlowski G, et al. Shining a light on species delimitation in the tree genus Engelhardia Leschenault ex Blume (Juglandaceae). Mol Phylogenet Evol. 2020;152:106918.

40. Lin RZ, Li RQ, Lu AM, Zhu JY, Chen ZD. Comparative flower development of Juglans regia, Cyclocarya paliurus and Engelhardia spicata: homology of floral envelopes in Juglandaceae. Bot J Linn Soc. 2016;181:279-93.

41. Christenhusz MJ, Byng JW. The number of known plants species in the world and its annual increase. Phytotaxa. 2016;261:201-17.

42. Hermsen EJ, Gandolfo MA. Fruits of Juglandaceae from the Eocene of South America. Syst Bot. 2016;41:316-28.

43. Geng YF, Hu GX, Wang S, Xu JC. Complete chloroplasts genome of the threatened Rhoiptelea chiliantha (Juglandaceae s.l.). Conserv Genet Resour. 2019;11:317-9.

44. Angiosperm Phylogeny Group (APG III). An update of the Angiosperm Phylogeny Group classification for the orders and families of flowering plants: APG III. Bot J Linn Soc. 2016:161:105-21.

45. Manchester SR. Early history of the Juglandaceae. Plant Syst Evol. 1989;162:231-50.

46. Martínez-García PJ, Crepeau MW, Puiu D, Gonzalez-Ibeas D, Whalen J, Stevens KA, et al. The walnut (Juglans regia) genome sequence reveals diversity in genes coding for the biosynthesis of nonstructural polyphenols. Plant J. 2016;87:507-32.

47. Zachos J, Pagani M, Sloan L, Thomas E, Billups K. Trends, rhythms, and aberrations in global climate 65 Ma to present. Science. 2001;292:686-93.

48. Zachos JC, Dickens GR, Zeebe RE. An early Cenozoic perspective on greenhouse warming and carbon-cycle dynamics. Nature. 2008:451:279-83.

49. Blokhina NI. Fossil wood of the Juglandaceae: Some questions of taxonomy, evolution, and phylogeny in the family based on wood anatomy. Paleontological J. 2007:41:1040-53.

50. Hu Y, Woeste KE, Dang M, Zhou T, Feng XJ, Zhao GF, Liu ZL, Li ZH, Zhao P. The complete chloroplast genome of common walnut (Juglans regia) Mitochondr DNA Part B. 2016;1:189-90.

51. Hu Y, Chen $X$, Feng $X$, Woeste KE, Zhao P. Characterization of the complete chloroplast genome of the endangered species Carya sinensis (Juglandaceae). Conserv Genet Resour. 2016;8:1-4.

52. Hu Y, Yan J, Feng X, Dang M, Woeste KE, Zhao P. Characterization of the complete chloroplast genome of wheel wingnut (Cyclocarya paliurus), an endemic in China. Conserv Genet Resour. 2017:9:1-3.

53. Ronquist F, Teslenko M, van der Mark P, Ayres DL, Darling A, Höhna S, Larget B, Liu L, Suchard MA, Huelsenbeck JP. MrBayes 3.2: efficient Bayesian phylogenetic inference and model choice across a large model space. Syst Biol. 2012;61:539-42.

54. Smith JF, Doyle JJ. A cladistic analysis of chloroplast DNA restriction site variation and morphology for the genera of the Juglandaceae. Am J Bot. 1995:82:1163-72.

55. Zhao P, Zhou H, Potter D, Hu Y, Feng X, Dang M, Feng L, Zulfiqar S, Liu W, Zhao G, et al. Population genetics, phylogenomics and hybrid speciation of Juglans in China determined from whole chloroplast genomes, transcriptomes, and genotyping-by-sequencing (GBS). Mol Phylogenet Evol. 2018;126:250-65. 
56. Wu ZY, Raven PH. Flora of China. Beijing: Science Press; St. Louis: Missouri Botanical Garden Press; 1999. pp. 139-62.

57. Wade EM, Nadarajan J, Yang X, Ballesteros D, Sun W, Pritchard HW. Plant species with extremely small populations (PSESP) in China: a seed and spore biology perspective. Plant Divers. 2016;38:209-20.

58. Fjellstrom RG, Parfitt DE. Phylogenetic analysis and evolution of the genus Juglans (Juglandaceae) as determined from nuclear genome RFLPs. Plant Syst Evol. 1995;197:19-32.

59. Woeste K, Michler C. Juglans. In: Wild crop relatives: genomic and breeding resources. Berlin Heidelberg: Springer; 2011. pp. 77-88.

60. Kou Y, Cheng S, Tian S, Li B, Fan D, Chen Y, Soltis DE, Soltis PS, Zhang Z. The antiquity of Cyclocarya paliurus (Juglandaceae) provides new insights into the evolution of relict plants in subtropical China since the late Early Miocene. J Biogeogr. 2016;43:351-60.

61. Leaché AD, Fujita MK, Minin VN, Bouckaert RR. Species delimitation using genome-wide SNP data. Syst Bio. 2014;63:534-42.

62. Eriksson O, Friis EM, Löfgren P. Seed size, fruit size, and dispersal systems in angiosperms from the early Cretaceous to the late Tertiary. Amer Nat. 2000;156:47-58

63. Bai WN, Yan PC, Zhang BW, Woeste KE, Lin K, Zhang DY. Demographically idiosyncratic responses to climate change and rapid Pleistocene diversification of the walnut genus Juglans (Juglandaceae) revealed by whole-genome sequences. New Phytol. 2017;217:1726-36.

64. Doyle JJ, Doyle JL. A rapid DNA isolation procedure for small quantities of fresh leaf tissue. Phytochem Bull. 1987;19:11-5.

65. Zhao P, Woeste KE. DNA markers identify hybrids between butternut (Juglans cinerea L.) and Japanese walnut (Juglans ailantifolia Carr.). Tree Genet Genomes. 2011;7:511-33.

66. Patel RK, Jain M. NGS QC Toolkit: a toolkit for quality control of next generation sequencing data. PLoS One. 2012;7:je30619.

67. Bankevich A, Nurk S, Antipov D, Gurevich AA, Dvorkin M, Kulikov AS, Lesin VM, Nikolenko SI, Pham S, Prjibelski AD, et al. SPAdes: a new genome assembly algorithm and its applications to single-cell sequencing. J Comput Biol. 2012;19:455-77.

68. Kearse M, Wilson A, Stones-Havas S, Cheung M, Sturrock S, Buxton S, Cooper A, Markowitz S, Duran C, Thierer T, et al. Geneious basic: an integrated and extendable desktop software platform for the organization and analysis of sequence data. Bioinformatics. 2012;28:1647-9.

69. Wyman SK, Jansen RK, Boore JL. Automatic annotation of organellar genomes with DOGMA. Bioinformatics. 2004;20:3252-5.

70. Lohse M, Drechsel O, Kahlau S, Bock R. OrganellarGenomeDRAW_a suite of tools for generating physical maps of plastid and mitochondrial genomes and visualizing expression data sets. Nucleic Acids Res. 2013:41:W575.

71. R Core Team. R: a language and environment for statistical computing, version 3.3.1. Vienna. Austria: R Foundation for Statistical Computing. [WWW document] URL; 2016. http://www.R-project.org/.
72. Li H, Durbin R. Fast and accurate short read alignment with BurrowsWheeler transform. Bioinformatics. 2009;25:1754-60.

73. Li H, Handsaker B, Wysoker A, Fennell T, Ruan J, Homer N, Marth G, Abecasis G, Durbin R. The sequence alignment/map format and SAMtools. Bioinformatics. 2009;25:2078-9.

74. McKenna A, Hanna M, Banks E, Sivachenko A, Cibulskis K, Kernytsky A, Garimella K, Altshuler D, Gabriel S, Daly M, et al. The Genome Analysis Toolkit: a MapReduce framework for analyzing next-generation DNA sequencing data. Genome Res. 2010;20:1297-303.

75. Li H. A statistical framework for SNP calling, mutation discovery, association mapping and population genetical parameter estimation from sequencing data. Bioinformatics. 2011;27:2987-93.

76. Bolger AM, Lohse M, Usadel B. Trimmomatic: a flexible trimmer for Illumina sequence data. Bioinformatics. 2014;30:2114-212.

77. Lanfear R, Frandsen PB, Wright AM, Senfeld T, Calcott B. PartitionFinder 2: new methods for selecting partitioned models of evolution for molecular and morphological phylogenetic analyses. Mol Biol Evol. 2016;34:772-3.

78. Katoh K, Standley DM. MAFFT multiple sequence alignment software version 7, improvements in performance and usability. Mol Biol Evol. 2013:30:772-80.

79. Posada D, Buckley TR. Model selection and model averaging in phylogenetics: advantages of akaike information criterion and Bayesian approaches over likelihood ratio tests. Syst Biol. 2004;53:793-808.

80. Posada D, Crandall KA. Modeltest: testing the model of DNA substitution. Bioinformatics. 1998;14:817-8.

81. Stamatakis A. RAxML version 8: a tool for phylogenetic analysis and postanalysis of large phylogenies. Bioinformatics. 2014;30:1312-3.

82. Edgar RC. Muscle: a multiple sequence alignment method with reduced time and space complexity. BMC Bioinformatics. 2004;5:113.

83. Kumar S, Stecher G, Tamura K. MEGA7: Molecular evolutionary genetics analysis version 7.0 for bigger datasets. Mol Biol Evol. 2016:33:1870.

84. Smith SA, O'Meara BC. treePL: divergence time estimation using penalized likelihood for large phylogenies. Bioinformatics. 2012;28:2689-90.

85. Bouckaert R, Heled J, Kühnert D, Vaughan T, Wu CH, Xie D, Suchard MA, Rambaut A, Drummond AJ. BEAST 2: a software platformfor bayesian evolutionary analysis. PloS Comput Biol. 2014;10:e1003537.

86. Drummond AJ, Rambaut A. BEAST: Bayesian evolutionary analysis by sampling trees. BMC Evol Biol. 2007:7:214.

87. Drummond AJ, Suchard MA, Xie D, Rambaut A. Bayesian phylogenetics with BEAUti and the BEAST 1.7. Mol Biol Evol. 2012:29:1969-73.

\section{Publisher's Note}

Springer Nature remains neutral with regard to jurisdictional claims in published maps and institutional affiliations.

Ready to submit your research? Choose BMC and benefit from

- fast, convenient online submission

- thorough peer review by experienced researchers in your field

- rapid publication on acceptance

- support for research data, including large and complex data types

- gold Open Access which fosters wider collaboration and increased citations

- maximum visibility for your research: over 100M website views per year

At BMC, research is always in progress.

Learn more biomedcentral.com/submissions 